\title{
Business Rescue DeCiSION MAKING THROUGH VERIFIER DeterminantS - ASK THE SPECIALISTS
}

\author{
Marius Pretorius and Gert Holtzhauzen \\ Department of Business Management, University of Pretoria
}

Accepted: July 2013

\begin{abstract}
Orientation: Business rescue has become a critical part of business strategy decision making, especially during economic downturns and recessions. Past legislation has generally supported creditor-friendly regimes, and its mind-set still applies, which increases the difficulty of such turnarounds. There are many questions and critical issues faced by those involved in rescue. Despite extensive theory in the literature on failure, there is a void regarding practical verifiers of the signs and causes of venture decline, as specialists are not forthcoming about what they regard as their 'intellectual property'.

Research purpose: This article introduces the concept and role of 'verifier determinants' of early warning signs, as a tool to confirm the causes of decline in order to direct rescue strategies and, most importantly, reduce time between the first observation and the implementation of the rescue.

Motivation for the study: Knowing how specialists confirm causes of business decline in practice could assist in analysis and deciding on strategies for the rescue earlier than can be done using traditional due diligence, which is time consuming. Reducing time is a crucial element of a successful rescue.

Research design and approach: The researchers interviewed specialists with extensive experience in credit for rescue and turnaround. An experimental design was used to ensure the specialists evaluated the same real cases to extract their experiences and base their decisions on.

Main findings: The specialists confirmed the use of verifier determinants and identified such determinants as they personally used them to confirm causes of decline. These verifier determinants were classified into five categories namely, management, finance, strategic, banking and operations and marketing of the ventures under investigation. The verifier determinants and their use often depend heavily on subconscious (non-factual) information based on previous experiences, rendering them 'irrational' in modern management perspectives.

Practical/managerial implications: Decision makers and affected persons could benefit from the insights obtained through this study. Confirming early warning signs through verifier determinants would be beneficial for entrepreneurs who are creditors, company directors, rescue practitioners, government regulators, court officials and educators alike.

Contribution/value add: Knowing the verifier determinants could assist decision making and improve the effectiveness of rescue strategies. Business rescue practitioners can improve their investigation of the affairs' activity by using such verifier determinants.
\end{abstract}

Key words: Turnaround, business rescue, decision making, verifier determinants

JEL: D700

\section{1}

\section{Introduction}

In a rescue or turnaround situation, decision makers that depend on financial reports find such reports inadequate and 'after the fact'. Often such data masks the reality that the rescue practitioner faces rather than being of assistance. Expert practitioners, however, develop verifiers, or what could be termed 'verifier determinants' of early warning signs, to enhance their decision making.
Turnaround managers and rescue practitioners face several liabilities when confronted with turnaround situations. Pretorius and Holtzhauzen (2008) have identified elements such as legitimacy, resource scarcity, strategy options, leadership capacity, data integrity and integration as liabilities. Verifier determinants specifically address the liabilities of data integrity and integration.

So far, the literature has been silent on verifier determinants; authors rather pool the elements of signs, signals, causes and indicators 
under the general collective of 'early warning signs' (EWS). Much work has been reported on financial EWS in particular because of their quantitative nature, while there is relatively limited reference to non-financial EWS, probably because of their abstract and often qualitative nature. EWS are mostly used for prediction of failure. Early warning signs theory serves as the main base on which verifier determinant theory is built. The use of verifier determinants is aimed at helping to make sense of turnaround and rescue decision making in order to effectively guide rescue plans. Figure 1 explores the concept of verifier determinants diagrammatically, to introduce the concept which is elaborated on as the unit of investigation once the literature has been reported.

In this article the authors set out to answer three questions: Do verifier determinants exist? If so, what are they? If these verifier determinants can be identified, how can they be applied in practice to improve decision making?

It is important to investigate ways to improve the functionality of rescue practitioners in order to both enhance rescue decision making and reduce time to implementation. Explaining the relationship between early warning signs and verifier determinants therefore has important practical value for the training of rescue practitioners and managers, entrepreneurs other decision makers and regulators.

This article starts by defining the concept of verifier determinants and how they can be used. Secondly, it links verifier determinants to early warning signs theory, which is well documented in the literature. Thirdly, it explains the experimental research design. Fourthly, the researchers discuss the findings, tracking substantiation and insights from the subjects to supplement the theory and the literature. Finally, the researchers draw conclusions about a framework for verifier determinant use and the application of verifier determinants during the rescue process.

\section{2}

\section{Background to the origin of verifier determinants and trends from the literature}

Business decline is part of business. It is generally perceived as negatively affecting people and firms; therefore legislation that supports debtor concerns has been instituted. Practice shows that sometimes business rescue practitioners (BRPs) understand neither the complexity of business decline (Pretorius, 2009), nor the various reasons that have been suggested for failure, with their many signs indicating the causes. These include diminishing resources, poor leadership, strategic issues, operational issues and combinations thereof. The many variables that determine how business failure occurs influence the decision making of the rescue process.

In response to changes in legislation there has been an explosion of consultants who view the opportunity to act as rescue practitioners as lucrative business. Such consultants originate from many backgrounds and include liquidators, legal professionals, accounting professionals and more - many without real business acumen. The ad-hoc licensing methodology adopted in South Africa contributes to the potential ineffectiveness of practitioners appointed. Two years into the new legislation, role players in the rescue industry already doubt BRP skills (Pretorius, 2013) and the cost of losing rescuable businesses due to this uncertainty needs to be calculated.

Scientific literature from developing countries on rescue is almost non-existent compared with that from the United States, Britain, Australia, Canada and Finland. Understandably, rescue practitioners protect their strategies as 'intellectual property' that constitutes their competitive advantage. The international literature incorporated in this study involved all scientific resources from the ABI-Inform, Ebsco-host, Proquest, Science Direct, Blackwell and other databases for titles published.

The following inclusion criteria for literature sources were applied: works concerning failure causes, warning signs, failure prediction, rescue strategy and firm decline were investigated. As for major seminal work, the date was not seen as a limitation, especially when an article was referenced widely; relevance and contribution to the body of knowledge on failure prediction, early warning signs and rescue strategy were paramount. Each article was scrutinised for confirmation of concepts, as well as additional concepts and variances under different conditions and 
contexts. When analysed, this research identified key concepts using grounded theory research.

The researchers designed the present study to identify and report verifier determinants for the key warning signs and causes associated with decline. They investigated situations in which specialists with many years of rescue and turnaround experience were interviewed under experimental conditions to establish the existence and use of verifier determinants for rescue decision-making.

\section{3}

\section{Unit of investigation and research objectives}

A verifier determinant in this study is defined as 'the root confirmer that a decision maker uses to validate the cause of decline or distress, underscores an early warning sign and focuses rescue strategy choice' (Holtzhauzen, 2010:15).

The meaning of a verifier in this study points to some factor or element that confirms, validates and ensures firstly that the cause exists and secondly that the early warning sign used to identify it is in fact present. Figure 1 shows the definition diagrammatically.

The term determinant therefore mainly reflects the agreement or consensus between the cause and the apparent warning sign verifier as shown in Figure 1. As a well known example of a verifier determinant, bankers would study an account of a suspect business client to identify payments containing 'round' figures. Several such figures would alert the banker to 'suspicious payments' to confirm money movements between accounts. Further investigation then often may confirm either cash flow pressure or, in extreme cases, pilferage to finance a luxurious lifestyle associated with the 'bullfrog' syndrome (Richardson, Nwankwo \& Richardson, 1994). This one verifier determinant can act as a 'trigger' in several categories, as will be explored in the findings of this research.

Figure 1

The concept and role of a verifier determinant as used by expert rescue practitioners

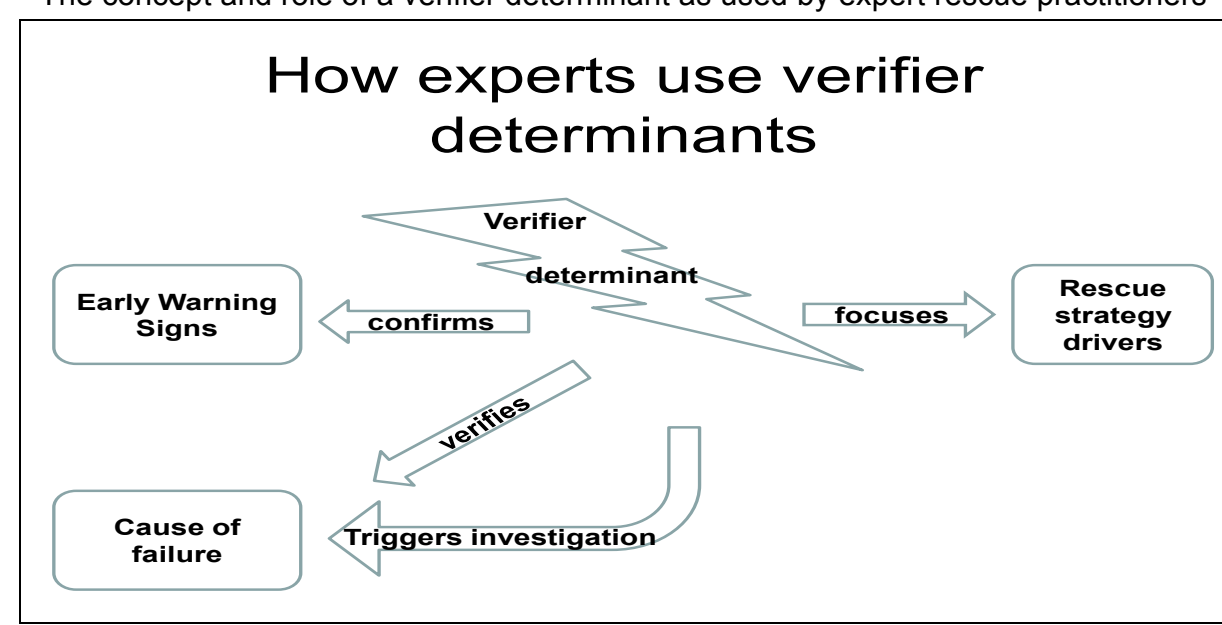

Therefore, the research objectives are:

- to identify and determine the existence of verifier determinants;

- to establish what they are; and

- to establish how specialists in the rescue field use verifier determinants to enhance decision making.

\section{4}

\section{Early warning signs theory preceding verifier determinant theory}

\subsection{Early warning signs theory}

Early warning signs are regarded as all types of events in business that point to the potential 
demise of that business. On a path of organisational decline, Cameron, Whetten and Kim (1987:126) choose to call the warning signs 'decline attributes'. Owing to their very nature as an underlying feature of a path of decline, these elements are occasionally not acknowledged or addressed as warning signs. Ueda (2004:612) argues that if a bank identifies a bad signal it then believes that the venture is likely to turn out to be unprofitable. Prominent in the literature is the identification of 'weak', 'poor', or 'problematic' management as an early warning sign. It is, however, very difficult to measure and quantify (verify) problematic, weak or poor management. Substantial debate is evident in the literature as attempts are made by various authors to clarify the phenomenon of early warning signs resulting from mismanagement.

In addition to the literature specifically referring to early warning signs, business failure prediction, successful versus unsuccessful and performing versus non-performing variables are all evident in the body of early warning signs literature. Consequently, it may be deduced that, as there are many definitions and descriptions of early warning signs, a working definition is desirable. A definition of an early warning sign arrived at by Devereux in a metaanalysis of causes and signs by Holtzhauzen (2010:43) is that as 'an internal or external extension of an event or factor or a combination of all, it may directly or indirectly highlight the pending demise of a business or business unit if not addressed and rectified in the course of business'. Ivanova and Gibcus (2003:17) refer to problematic management as 'negative behavioural traits'. Back (2005:843), on the other hand, refers to early warning signs as the 'focus of financial difficulties and behavioural issues', while Carmichael and Stacey (2006:3) focus on 'managerial success variables' such as accountability, initiative, boundaryless thinking and integrity. Bates (2005:345) focuses on deficiencies in the 'skills set' of owners and managerial 'success variables' as warning signs. Some authors, such as Moy and Luk (2003:207), refer to early warning signs as 'obstacles' and 'problem types' for growth.

One of the main threats to business viability is management and/or directors who contemplate fraud. In line with this, Bower and Gilson (2003:20) state that fraudulent underreporting of expenses (and other financial performance measures) results in extremely high costs in order to rectify the position. Fraudulent business practices are not limited to misrepresentation but also include statutory noncompliance. Mueller, McKinley, Mone and Barker (2001:25) maintain that, in the process of rationalising the causes of organisational decline, management must form an opinion on the stability of those causes and debate them. This is, however, a constricted, simplistic view of early warning signs.

Singer (1995:325) concludes that 'constructs such as poor management, strategy, environment, and industry structure are in themselves inadequate explanations of new venture failure or success'. Early warning signs shaped from a focus on the skills set of owners contemplate, according to Lussier (1995a:8), 'non-financial business success versus failure variables'. Banfield, Jennings and Beaver (1996:94) focus mainly on the up-skilling of management, addressing need and demand. Three broad management areas that need to be monitored were identified in Grant Thorntons catalyst issues (2004a:1). These are finances, operations and strategic planning. In the broader sense these essential aspects need to be dealt with by the rescue practitioner and entrepreneurs business and strategic rescue planning. Beaver and Jennings (2005:12) describe the management process as a progression which has highly personalised preferences, prejudices, attitudes, skills demand, and technical and educational needs. They also focus on control by the bureaucratic and hierarchical environment over critical decision making. Management plays a significant role in identifying and disclosing early signs of decline. It is, however, clear that when early warning signs begin to appear, the business is already in a sub-normal situation.

Gilmore, Carson and O'Donnell (2004:349$357)$ refer to situations where early warning signs appear as 'risky situations'. Some authors, such as Nutt (2004:13), Franks and Sussman (2005:30), Fraser (2005:448), and Cressy (2006:113), debate fortune as playing a part in the failure of a successful business; this phenomenon is described by Elenkov and Fileva (2006:135) as 'bad luck'. By contrast, 
Harvey (2002a:3) concentrates on examining the 'value-creating potential of primary activities' as early warning signs. Pretorius (2008:412) discusses (1) human causes associated with failure in the context of early warning signs; (2) internal and external causes associated with failure; and (3) structural causes associated with failure. He maintains that it is crucial to identify distress warning signs in the business in good time if an attempt is to be made to save the business.

Seminal work on early warning signs has been largely summarised by academics such as Cannon and Edmundson (2005), Collard (2002), Lohrke, Bedeian and Palmer (2004), McGurr and DeVaney (1998), Moncraz and Kron (1993), Sharma (2001), Sharma and Mahajan (1980), Stead and Smallman (1999) and Tang and Chi (2005). It appears that these authors use the following phrases inconsequently to describe 'early warning signs': success versus failure variables, causes of decline and or failure, warning indicators for business decline, performing and non-performing variables, root causes for decline or failure, warning indicators, material defects, external and internal factors, distress variables, problems and challenges.

A wide range of terminology and application therefore exists around the early warning signs theory. Much overlapping of meaning is also evident. This article aims to eliminate some of this overlapping by the use of 'verifier determinant' as the term.

\subsection{Verifier determinants}

Turnaround situations are normally complex and contain many vagaries that influence decision making. At best, some of the frameworks from the literature that assist such decision making and strategising are guidelines only; they require interpretation and situation application, as no two turnaround situations are the same (Pretorius, 2008).

Verifiers are used to confirm the existence of problems in the business or in the business environment, as environmental scanning units seem to be unable to respond to what Ansoff (1975:25) calls 'weak signals'. Stubbart (1982:143) concludes 'we have too many places to look and too few theories of how significant environmental change can be linked to the business's plans'. The introduction of verifier determinants in this study is intended to fill the gap in this regard by focusing the investigative stage of a rescue situation. In order to achieve the research objective of identifying verifier determinants, different opinions from a business, an accounting and a legal platform were presented. These opinions are given within a framework of early warning sign identification and rescue practice.

This article builds on the early warning signs theory to establish verifier determinants that could guide entrepreneurs and rescue practitioners in the timely planning of the immediate rescue and future sustainability of an enterprise. Verifier determinants, once identified, could help to authenticate warning signs and could be used progressively in the diagnostic phase of the rescue process. The effectiveness of business rescues depends on the choice of strategy, of which the verifier determinants may be an important component. As soon as they are identified and confirmed, the verifier determinants can assist in defining the rescue event. Verifier determinants are used to confirm early warning signs, and can be used extensively to confirm causes, focus on the correct warning sign and substantiate the issues to consider when compiling the rescue plan. Identifying verifier determinants may also help to uncover other hidden critical issues.

The use of verifier determinants is essential when attempting to classify the warning signs used in the enormous array of business applications such as operational non-efficiencies. These verifiers could also contribute to the day-to-day monitoring of the business, if used as a prolonged business activity. This qualitative research has therefore made a unique contribution to confirming early warning signs by developing the verifier determinants, each with its own set of variables.

\section{5}

\section{Research design}

This section covers three aspects of the research design. These are the research approach, the experimental setting as the research strategy, and the research methodology. This is similar to the design that Serfontein, Basson and Burden (2009) describe. 


\subsection{Research approach}

The research approach was exploratory and qualitative in nature. It identified and explained the embedded experiences of specialist rescue practitioners. These specialists had been involved in many informal turnarounds and rescues as bank officials. In this experimentally designed study in which specialists evaluated real cases that covered recent rescues, several unanswered questions arose. Three are particularly interesting for this study.

Firstly, the researchers needed to identify whether the verifier determinant concept did exist, knowingly or unknowingly, in the minds of the deliberately selected expert subjects. Subjects could be using the concept without being able to name it as a concept, or consciously as a method of confirming the causes of decline or early warning signs.
Secondly, the subjects were given three comprehensive case studies to evaluate in their own time as preparation for the interviews (to later determine how verifier determinants were applied in their evaluation process). During the interviews they were probed with questioning at different levels. At the start questions were open ended, then became more specific as the interviews progressed. Once verifier determinants had been identified, the subjects were asked to compare the cases and identify the verifier determinants for each case. Possible discrimination with verifier determinants was sought.

Finally the researchers wanted to know how the specialists used the information obtained with the verifiers to inform the rescue plan, and whether verifier determinants contributed to saving time between the analysis and the steps of the rescue plan process. Table 1 summarises the research design.

Table 1

Research design components based on the adapted design description of Yin (2003:21).

\begin{tabular}{|l|l|}
\hline \multicolumn{1}{|c|}{ Component } & \multicolumn{1}{c|}{ Description } \\
\hline Research question or problem & Do verifier determinants exist, and if so, how are they used? \\
\hline Context & Business rescue and turnaround situations \\
\hline Propositions* & $\begin{array}{l}\text { Verifier determinants do exist. } \\
\text { Verifier determinants are used to inform decision making. } \\
\text { Verifier determinants can inform the rescue plan. } \\
\text { Verifier determinants save time in the decision making process. }\end{array}$ \\
\hline Unit of investigation & $\begin{array}{l}\text { Primary - verifier determinants } \\
\text { Secondary - decision making }\end{array}$ \\
\hline Unit of analysis & Experienced specialist turnaround and rescue practitioners in banking industry \\
\hline Logic linking the data to the \\
propositions & $\begin{array}{l}\text { Specialist rescue practitioners use verifier determinants to enhance their decision making. } \\
\text { They use conscious and unconscious elements to achieve this. Carefully extracting this } \\
\text { information could lead to the identification of these verifier determinants. Sense making } \\
\text { through the research could lead to a framework to enhance rescue plans and improve } \\
\text { time efficiencies. }\end{array}$ \\
\hline $\begin{array}{l}\text { Criteria for interpreting the } \\
\text { findings }\end{array}$ & $\begin{array}{l}\text { Factors, issues and methods that subjects use to verify signs and causes } \\
\text { Processes that subjects use to verify signs and causes } \\
\text { Practical application of verifier determinants }\end{array}$ \\
\hline * The propositions were set to structure the research process and support the research question. \\
\hline
\end{tabular}

\subsubsection{Key scientific beliefs}

In attempting to answer these questions, the researchers were aware of their own methodological values, beliefs and philosophical assumptions. These assumptions could influence how they conducted the research; they stated them in order to understand the intellectual climate in which they conducted the research.

\subsubsection{Ontological positions}

These comprise the researchers views on the very nature and essence of research reality.
Researcher A is an objective realist who believes that knowledge comes from facts associated with the cases and the context. If the researcher found repeated mentions of applications, preconditions, causes and responses, he could 'generalise' them. His interest was mainly business strategy during decline.

Researcher B is a constructionist practitioner who believes that situations can be explained, especially when one has participated in its processes. Peoples views, actions, reactions, interactions, social relations, social and cultural 
practices, rules and values reflect their experiences that guide decision making. Therefore, understanding such subjective experiences and interpretations may uncover unknown relationships and lead to improved insights of the experienced reality. His interest was mainly business principles applicable to the turnaround and rescue situations

The personal experiences of the specialist subjects and their interpretations of the different contexts of each case were interesting. The specialists shared their experiences willingly and responded openly to all the questions the researchers asked during the interviews.

\subsubsection{Epistemological positions}

The theory of knowledge (epistemology) of the researchers diverged to some extent. This allowed for interplay on how one can discover decisions about social phenomena and how one can demonstrate knowledge.

Researcher A worked primarily from a scientific paradigm, particularly in the primary stages. However, he changed this during the process to a consultant paradigm. He had had experience of rescues and a business failure himself. He had worked as an academic as well as a strategy and turnaround consultant. This influenced his search for factual directives, patterns and answers to correct future situations of a similar nature.

Researcher B worked from a business rescue practice paradigm and looked for a description of the verifier determinant construct based on intuitive experience as a rescue practitioner over 15 years.

Thus, both authors were subject to their own biases and therefore we chose structured datagathering methods (interview and repertory grid comparisons) to capture the activities and experiences of the subjects during their evaluations.

\subsection{Experimental setting using case study evaluations as a research strategy}

The researchers used interviews to extract the phenomena in a real-world context where the boundaries between phenomena and context are not clear. Yin (2003) suggests that the uniqueness of individual experiences is a sufficient rationale for using experimental design based on case studies that eliminate contextual variation.

The specific cases the researchers presented to the subject respondents were pre-selected to exhibit different levels of distress, and were 'real-life' cases that had been recently experienced by the bank. It was an important breakthrough to identify these experts, because as banking officials of many years standing they shared their thinking openly; there was no real benefit to their trying to protect any 'intellectual property', as would be the case when private consultants were interviewed. Using a selection of cases ensured that the subjects were bound to comparable application context and eliminated different background expertise that might be industry-specific. This experimental design eliminated the variation that originates from the complex circumstances that could accompany rescues in the real world.

The reasoning the researchers used was mostly inductive to explore the subjects understanding, experiences, interpretations and knowledge building for the different cases they judged.

\subsection{Research method}

\subsubsection{Research setting}

The researchers interviewed nine specialists purposively selected to participate in this study. Industry specialists with practical experience were identified in the target organisation (a commercial bank) and these specialists were selected to participate. Three case studies (from a set of six representing two each from standard, sub-standard and special mention categories) were selected at random for each specialist, which resulted in each participant having a sample in which at least two of the main categories of Basel II rating are represented. The case studies were distributed to the participants two weeks prior to the scheduled interview. During this period the subjects were requested to prepare themselves adequately for the interview process. This preparation was estimated to take at least three hours. The subjects were then invited to an interview and encouraged to bring the case studies and all preparatory notes with them. 
The estimated time allotted for the interview was three hours, although the first interview took four and a half hours to complete. However, as the researchers gained experience in the interview process, the time spent on the interviews was reduced. Subsequently, the average time per interview was calculated at three hours forty minutes. In order to keep the interview process unbiased, the interview content, such as the process to be followed and questions to be asked, was not disclosed to the subjects prior to the interview. Subjects were also reassured that there would be total anonymity and that the results would only be used for the research project.

Subjects participated voluntarily. It was found that they were relaxed when answering the questions, since these were based on their field of expertise. It is believed that these positive interview conditions led to unbiased sharing and meaningful conclusions drawn from the discussions of their perceptions and experience.

\subsubsection{Background and setting for case evaluation process}

For the purposes of this study, recent, real-life business profiles were obtained from the bank archive and used. Care was taken to disguise case names and potential recognisability by subjects. The real-life cases comprised a stratified random selection drawn from existing businesses in a commercial banking environment. The businesses were geographically spread throughout South Africa and the selection was not limited to one province only. The choice of cases was of the utmost importance to ensure that selection bias was ruled out. Research cases were obtained from an organisation with a comprehensive database of business data, which made it relatively easy to randomly select the sample of real-life cases.

For selecting the case studies to be evaluated, the researchers relied on businesses that were already subjected to Basel II Accord categorisation criteria. This research chose to select real-life cases with an in-depth longitudinal character. Cases were selected at random, provided that they had at least three years historical financial and other relevant data. This was important to ensure equal representation of the selected cases. In a rescue situation, a commercial bank is 'exposed both ways', as the bank is a key component in any rescue attempt, be it informal or formal.

The existing Basel II risk rating was applied to each business case and then used in selecting two cases in each category, Standard, Special Mention and Sub Standard. Within each case, the following information was supplied: Curricula vitae of managerial staff, historical files consisting of business background, management succession, market and product information, staff growth and considerations, changes in industry type and business model, three years audited financial statements to establish growth, and finally cash-flow projections. Care was taken to give equal information for every case to avoid possible bias.

The primary aim of the case research and the interview process was to establish the perceptions of specialist subjects in identifying early warning signs, causes and verifier determinants linked to the risk levels (Basel rating).

\section{6}

\section{Entrée and researcher roles}

The researchers approached the subjects (respondents) based on their involvement in senior committees on rescue funding meetings (all distress cases of each branch were referred to these meetings for discussion and ultimate action by the institution). These types of meeting were typically held weekly and included teleconferencing to involve the key senior decision makers of the different credit divisions within the provincial structures of the bank. The two participating researchers, each with his own approach to investigating and questioning, participated in the process for all the interviews.

Both researchers gathered their own field notes during the interviews. The notes led to some interaction between the two researcher paradigms. This interaction of paradigms emphasised the value of the supplementary and complementary character of the two ontological positions. The researchers investigated the outcomes of the comparative evaluations separately to explore the interrelationships between identified constructs. 
7

\section{Sampling}

The researchers approached the subjects individually, requesting participation. They were purposely selected based on their specialist expertise and experience as well as their decision-making positions within the organisation. They agreed to participate as they had known the one researcher very well over many years as a colleague.

The subjects were all older than 40 years of age and had at least 20 years banking experience gathered while working for different institutions previously, of which at least 15 years was in credit, risk and rescue. All had postgraduate qualifications, but the key determinant was the fact that their job mandate was one of decision making over the ultimate direction of such cases in the respondent organisation.

\section{8}

\section{Data collection methods}

The phenomena the researchers investigated involved on the one hand the subjects perspectives: thinking, experiences and decision making, and on the other the real-life cases of distressed ventures, with their specific contexts (see also Table 1). Therefore, the boundaries between the subjects and the venture contexts were clear, as they had no prior involvement with the specific cases. This meant that the researchers could pursue all sources of evidence to find convergence and divergence.

Additionally, because the cases were recent, there was sufficient access to case documents, financial statements, ratings criteria from Basel II and background information to produce comprehensive material for the subjects to evaluate.

At first, the initial observations of the subjects were important in understanding the comparative aspects of the case ventures and the selection of similarities (or differences) between the cases, as suggested by the repertory grid methodology (repgrid) (Feixas \& Alvarez, 2006) applied. These initial observations also contained the subjects own interpretations of the issues at hand for each case.
Secondly, after the researchers had held the in-depth interviews and applied the repertory grid evaluations, they used their interview notes and interpretations to make sense of them. The interview protocols for repgrid methodology included:

In your opinion,

- Which two cases are more similar (compared with the other one)?

- What early warning signs did you observe?

- Why is the one (case) different from the other two?

- What caused the signs in your opinion and why do you say this?

- How did you confirm the existence of the sign/cause?

- What is the main differentiating construct?

- Does this construct fall into the category of an early warning sign or a verifier determinant?

- How important was the verifier determinant in your decision making?

- The case which was not selected - why was it not selected?

- What would be the constructs of your rescue proposal?

The repgrid methodology was also applied to establish the constructs (factors) of verifier determinants, as verifiers introduce elements which provide for illogical, subconscious, judgemental information that is not contained in present early warning sign theory. The repgrid methodology concentrates on the criteria which influence the subjects choices. These criteria are the specialists difference in experience, which will, when combined, lead to the formulation of a construct. The repgrid methodology effectively deals with interviewer concerns such as interviewer bias, specificity, and over-dependence on the knowledge of interviewers. The researchers could probe for explanations about the answers the subjects gave throughout the interviews.

The researchers individually and separately interpreted the interview outcomes by searching for key issues, insights, similarities and anomalies, together with their own field notes. Once they had identified the issues, they coded them.

The subjects' cognitive experience and knowledge of the business case was also then 
recorded, the key constructs were identified, the main early warning sign category was identified and subsequently, most importantly, the verifier determinant was identified. A record sheet was used to annotate every discussion topic and/or interview question asked.

\section{9}

\section{Data analysis}

Though there was only one key source of evidence (the specialists), the researchers used investigator triangulation (Yin, 2003:98) to extract as much richness as possible. Through the many views of the evidence, specifically those of the specialists own version of their experiences, insights and interpretations, each evaluation, in-depth interview notes, the evaluation forms of the case comparisons, interviews and checking the researcher interpretations, the researchers identified and recorded aspects relevant to the research propositions. They mapped the elements that served as verifier determinants to understand elements, sequences, events, effects, relations, causation, outcomes and timelines. As the cases were real, there was also a record for each within the system to use as reference.

\section{0}

\section{Strategies used to ensure quality data}

As there was only one source of evidence, the researchers firstly used investigator triangulation. We checked quality as the interviews progressed. Here we asked the specialists, as the key informants, to judge the researchers interpretations of the different issues. As the focus of this study was mainly explanatory, the interview process focused on how things were perceived as the specialists described them, thus using 'explanation building' to improve internal validity (Yin, 2003:34).

\section{1}

\section{Reporting the findings}

The researchers reported the findings by stating the key observations and responding to the research propositions individually. The style was firstly exploratory, to identify the verifier determinants, and thereafter explanatory, to describe verifier determinants and how they are applied in the evaluation process and the rescue plan, and if they have potential timesaving benefits (to find support, or the lack of it, for the propositions; also see Table 1).

The findings show support for the proposition that specialist rescue practitioners do use verifier determinants to confirm early warning signs and causes of turnaround situations and apply such verifier determinants to the rescue plans.

\section{2}

\section{Findings}

The first research objective was to describe the concept of verifier determinants and their relation to early warning signs theory, to lead the identification of such verifier determinants in practice. The second research objective was to determine how verifier determinants are used in decision making, and the final research objective was to describe how verifier determinants inform rescue plans and their effect on time reduction.

\subsection{Findings linked to Proposition 1: Verifier determinants can be identified}

The detailed analysis of responses by the specialist subjects yielded some interesting and salient similarities pertaining to their thinking about early warning signs, causes and verifier determinants associated with each case they evaluated. During the interviews, it became clear that some of the opinions were similar, but with varying denotations and terminology. Instances where the outlook on approaches was the same were therefore grouped in the relevant categories.

Firstly, all subjects had definite 'thinking structures' by which they judged the presented situations and made their comparisons. While some could not always immediately and rationally verbalise their thinking and reasoning behind certain judgements, it was possible to extract it through rigorous questioning by the interviewers. 
The subjects identified several verifier determinants related to each category. As expected, these verifier determinants showed a classic resemblance to the warning signs identified in the literature reviewed. The participants were also able to identify the same elements that are used in the Basel II findings, which demonstrate the participants high level of knowledge about applied financial evaluation methods. Moreover, the subjects had no trouble in accurately placing the case studies in low, medium, or high-risk categories.

Five categories of verifier determinants were identified by the subjects during the interviews. This section only reports the verifier determinants for each category and is supported by a simplified case-in-point example, as reported during the interviews. Verifier use is elaborated on under Proposition 2.

\subsubsection{Management verifier determinants}

Twelve managerial verifier determinants were used by the specialists. These include (in no particular order): no or limited management information system in operation; managers education does not complement business type; decision maker that is 'scapegoating' (blaming); inflexibility when making decisions regarding change; decision maker is absent from work and important meetings; impulsive decision making; decision maker not able to recall management information immediately (has to ask others); absence of up-to-date management accounts; important decisions are made on the golf course; decision makers personal problems - health or marriage issues overshadow business focus; super cars and toys and finally a business that outgrew decision makers skill set.

Case-in-point example: If, when one is visiting a business and in consultation with its management, it appears that management is unable to recall management information immediately (and relatively accurately) and has to rely on others to submit such information, it verifies that management expertise is lacking in the business.

\subsubsection{Financial verifier determinants}

Twelve financial verifier determinants were identified by the specialists and include: labour cost that is disproportionate for the type of business; absent or unrealistic cash-flow projections; a high risk (or one big project) dependence; late submission of financial information in an attempt to postpone unfavourable news; sensitivity on tax avoidance; not analysing internal financial information; underutilisation of assets; creative accounting; pricing or discounts for cash generation; slowing down and stretching payments to suppliers in an attempt to generate cash; high executive remuneration; and, finally, dividend payouts that are unstructured and considered too high.

Case-in-point example: If, when one is visiting a business and in consultation with management, management is over-sensitive about tax evasion and there are signs of creative accounting, this verifies that management is aware of and potentially hiding/distorting financial facts; at the same time the integrity of all other financial information becomes suspect.

\subsubsection{Strategic verifier determinants}

Ten strategic verifiers were identified by the specialists namely: forced growth attempts (through mergers and acquisitions); overambitious growth strategy; not willing to deviate from strategic plan; non-responsive to small inefficiencies; unclear strategy for product and market; inability to adapt to business life cycles; problematic fit between strategic posture, structure and industry life cycle; overexpansion of capacity without considering market; lack of strategy to combat decline; lack of fusion between strategic issues and everyday operations.

Case-in-point example: If the decision maker is unable to accept, respond or adapt to change (demanded by the market), but concentrates on internal growth and operations only without having strategic plans in place, this clearly indicates a weak strategic position.

\subsubsection{Operational and marketing verifier determinants}

Ten operational and market verifier determinants were identified by the specialists, namely: inappropriate channels of distribution; ageing production techniques; decision maker not knowledgeable about new technology; 
misinterpretation of competitive advantage; declining emphasis on advertising; poor service or products; reliance on one customer; failure to respond to high cost structure compared with competitors; market forces ignored in planning; core markets moving away from location.

Case-in-point example: A practitioner is visiting the business and investigating the operational issues, such as distribution channels, and inefficiencies due to inappropriate channels and the management of 'proof of deliveries' and correctness and validation of debtor statements verify poor operations. This may show decentralised distribution centres are potentially driven by past decisions rather than sound business choice based on current profitability, which then confirms poor operational decision making.

\subsubsection{Banking verifier determinants}

Six banking verifier determinants were identified by the specialists, namely: regular stop payments on creditor obligations; increase in short-term requests for cash flow purposes; declining deposit balances and/or returned cheques; rounded amounts paid to creditors; overdraft advance funding other purposes such as asset acquisition; funding structure does not complement business model.

Case-in-point example: When one is investigating financial and bank statements, the existence of rounded amounts may confirm fund channelling. This then triggers investigation of relevant accounts to determine the financial 'merry-go-round' or 'kite-flying' used by management. Rounded amounts can also verify arrangements to 'repay' creditors over an arranged period of time. Table 2 lists the verifier determinants identified in this study.

Based on the below, the research found enough support for the proposition that verifier determinants could be identified, as subjects contributed examples and confirmed their existence.

Table 2

Verifier determinant summary with typical core elements

\begin{tabular}{|l|c|l|}
\hline \multicolumn{1}{|c|}{ Verifier determinant } & $\begin{array}{c}\text { Number of } \\
\text { elements in } \\
\text { category }\end{array}$ & \multicolumn{1}{c|}{ Typical core elements } \\
\hline Management & 12 & $\begin{array}{l}\text { No or limited management information system in operation; decision } \\
\text { maker that is 'scapegoating' (blaming). }\end{array}$ \\
\hline Financial & 12 & $\begin{array}{l}\text { Labour cost that is disproportionate for the type of business; absent } \\
\text { or unrealistic cash-flow projections. }\end{array}$ \\
\hline Strategic & 10 & $\begin{array}{l}\text { Over-ambitious growth strategy; non-responsive to small } \\
\text { inefficiencies. }\end{array}$ \\
\hline Operational and marketing & 10 & \begin{tabular}{l} 
Inappropriate channels of distribution; ageing production techniques. \\
\hline Banking
\end{tabular} \\
\hline
\end{tabular}

\subsection{Findings linked to Proposition 2: Verifier determinants are used to inform decision making}

Once the subjects understood the concept of verifier determinants (the unit of investigation) and what the researchers were looking for, they could easily describe the 'tools' they applied to confirm relevant issues and elaborate on why and how they used them. They could then contribute more information about the usage of the different verifier determinants. This section is supported by two anecdotal evidences to explain the role of the verifier determinants in practice.
The nature of verifier determinants appears to be less rational and logical, and more intuitive and experience based. While this might appear to be counter to proper decisionmaking principles, this study shows the praxis of how it really happens in practice when practitioners face decision-making situations.

In one anecdote, a subject arrived at the premises of the business under rescue and observed several cars with 'personalised' number plates parked outside. This verified the 'super cars and toys' under the management category of determinants, and further investigation confirmed large outflows into car 
leases for family members - an expense outside the business focus.

In another anecdote, the subject visited the factory shop and overheard the shop assistant informing a customer that he could not pay with a credit card as this was a cash shop only. Under the financial category it represented 'pricing and discount verifiers', and later proved to be linked to deliberate pilferage from the business as well as false write-offs.

As with the above, the subjects could share case examples of how they used the verifier determinants to assist their further analysis and eventual decision making. Much support was thus found for Proposition 2.

\subsection{Findings linked to Proposition 3: Verifier determinants can inform the rescue plan}

Subjects reported that their rescue plans were informed by the verifier determinants. The verifier determinants act as key focus factors in the rescue plan. As a case-in-point example, after overhearing the cash store-only remark, the subject appointed a forensic auditor to trace the stores impact on the cash shortage, leading to the finding of several millions of rands $(1 \$=$ $8+$ rand) fraud. This informed the rescue plan to include a proper accounting and control system pertaining to the shop, as well as a daily banking instruction. As the verifier determinants confirm causes of the decline, it follows logically that they have a direct relation to the key focus areas of the rescue plan. Support for Proposition 3 was therefore established.

\subsection{Findings linked to Proposition 4: Verifier determinants save time in the rescue process}

Subjects regularly used the slang term 'quick and dirty' to explain their initial analysis and confirmation procedures that involved the verifier determinants. They use the 'quick and dirty' short cut to make, at the earliest possible point in time, a 'proportionate judgement' related to the category of verifier determinants involved. They report that they make the early decision based on the verifier and thereafter follow the standard analysis (focused due diligence) procedures required by policies of their institution. On the basis of the early decision, they can however act pre-emptively in the strategies that they select for the rescue, as 'time is of the essence'. 'For me,' one subject stated, 'it is damage limitation tricks that I use; you dont have time to play with.'

The role of verifier determinants seems to be accentuated during the early analysis phase of the turnaround process. The 'non-factual' nature of the verifier determinant contributes to the initial short-cut approach. Therefore, the researchers found support for the proposition that verifier determinants could save time in the rescue process.

\section{3}

\section{Discussion and conclusions}

The discussion expands on some key observations about the existence of verifier determinants as a concept, and the use of verifier determinants during analysis of a rescue situation and creation of the rescue plan.

Firstly, the subjects confirmed that early warning signs do exist, as well as confirming the general categories as described in the literature; namely, management, financial, operational/marketing, strategic and banking warning signs. During interviews, they would use phrases such as 'Ratios are worsening' and 'There is a management problem'. Subjects could identify the early warning signs with relative ease from the case material provided and could easily speculate about the potential causes for them. When probed/challenged about how they would confirm these early warning signs, they identified the need for visiting the venture and interviewing the owner/manager as well as staff members. They therefore had to reflect on previous experiences to identify what they would use to verify their 'suspicions'. This need for the visit and interview suggests that alternative indicators are used as verifier determinants (compared with the basic warning signs themselves) and this is therefore a key finding of this study.

Secondly, the nature of the verifier determinants that the subjects used varied from rational relationships between elements, to 
perceived connections, to personal biases that appeared to have no relationship to the issues they were linked with. Nevertheless, these were the constructs that subjects identified. The financial verifier determinants were favoured by most of the respondents as being of high importance. This was to be expected, as the research was conducted in a financial institution and was probably related to the specific requirements under which subjects operated. Furthermore, financial verifier determinants are largely measurable.

Thirdly, while the verifier determinants could be categorised, there were individual verifier determinants that could easily belong to more than one category, which suggest the borders between categories being vague in many cases. 'Not analysing internal financial information' as a verifier determinant could easily be construed to verify poor management, though it was grouped under financial verifiers. Several of the verifier determinants have a similar characteristic. Nevertheless, the importance of the correct category is secondary to the fact that these specialists do use verifier determinants, both consciously and subconsciously, to improve their analyses of the situations and consequent decision making.

Finally, the verifier determinants are often interrelated and indirectly connected. In the case of the cash store quoted above, the following subject statement serves as a good example of the interrelatedness. 'When arriving at the premises of a filing enterprise for the first time, I saw several motorboats and water skis (super toys) standing in the yard. I knew that the business was small and wondered about where the money came from. The comment in the cash store confirmed the other verifier determinant and directed the investigation'. Often management and financial verifiers are somehow connected.

The study begins to pave the way for rescue practitioners to become aware of the useful application of alternative 'tools' to overcome the liabilities of turnaround managers, as described by Pretorius and Holtzhauzen (2008). It has proposed practical tools that could be taught to address the liability of data integrity in particular.
13

\section{Implications, limitations and future research}

To generalise using the results of nine specialists only may appear inappropriate. However, the case studies allowed for comparative evaluations and some interesting convergence between subjects. The richness of data through the experimental design confirms the complexity of turnaround situations, their analysis and the decision making involved during strategising to create a rescue plan. Future research should attempt to replicate the study with rescue practitioners under Chapter 6 or confirm the use of the identified verifier determinants through quantitative analysis.

Secondly, the qualitative nature of the data is subject to the perceptions and interpretations of the researchers and their research interests, despite all their attempts to be objective. Further research should focus on seeking to quantify data collection by expanding the research strategy to include survey analysis.

Thirdly, the absence of measurable and factual details meant that the interpretation depended mainly on the subconscious and unconscious interpretations of factors based on the interpretations and experiences of the subjects. One should see the findings in this context.

Although the researchers could not generate deterministic facts for practitioners to use, they did identify some interesting directives for further research.

Fourthly, even though the subjects could not prove any relationships between verifier determinants that they used and the factual turnaround situations, the existence of such verifier determinants is undeniable. Rather than the use of such 'irrational' tools being opposed, they should rather be embraced but with the necessary caution.

Finally, the implications of this research point towards the value of experience for rescue practitioners. The question that arises is how to gain these experiences unless one is directly involved in business rescue. Future research should look into the quantification of the verifier measurements through factor analysis to determine the use of elements under each verifier. 


\section{Acknowledgements}

The authors are indebted to the financial institution which participated and gave access to the case material and staff, as well as the subjects for their time and effort that enabled Gert to complete the PhD degree. We also want to express our gratitude towards the anonymous reviewers for their inputs to improve the paper.

\section{References}

ANSOFF, H.I. 1975. Managing strategic surprise by response to weak signals. California Management Review, 18: 21-33. Available at: ProQuest ABINFORM Global: http://0-search.proquest.com.innopac. up.ac.za/docview/206249450/fulltestPDF/12D7E79899F27E93B34/6?accountid=14717 [accessed 201001-23].

BACK, P. 2005. Explaining financial difficulties based on previous payment behaviour, management background variables and financial ratios. European Accounting Review, 14(4):839-868. Available at: EBSCOHost: Business Source Premier: http://0-web.ebscohost.com.innopac.up.ac.za/ehost/pdfviewer/pdfvie wer?vid=3\&hid=17\&sid=78b2d3a5-ce7c-4d3f-a2eb-a0c2d43922e5\%40sessionmgr11 [accessed 2006-01-16]. BANFIELD, P., JENNINGS, P.L. \& BEAVER, G. 1996. Competence-based training for small businesss - an expensive failure? Long Range Planning, 29(1):94-102 Available at: ScienceDirect: http://0-www. sciencedirect.com.innopac.up.ac.za/science?_ob=MImg\&_Imagekey=B6V6K-3VWPKX4-B$1 \&$ _cdi $=5817 \&$ _user $=59388 \&$ _pii $=0024630195000704 \&$ rig $=$ browse\&_coverDate $=02 \% 2 \mathrm{~F} 29 \% 2 \mathrm{~F} 1996 \&$ s

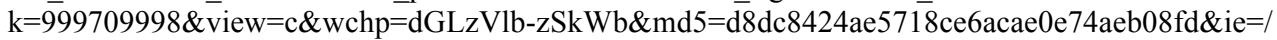
sdarticle.pdf [accessed 2005-12-14].

BATES, T. 2005. Analysis of young, small businesses that have closed: delineating successful from unsuccessful closures. Journal of Business Venturing, 20(3):343-358. Available at: ScienceDirect: http://0ww.sciencedirect.com.innopac.up.ac.za/science?_ob=Mlmg\&_magekey=B6VDH-4C7VXVG-1$1 \& \_$cdi $=5983 \&$ _user $=59388 \&$ _pii $=$ S0883902604000308\&_origin $=$ browse\&_zone $=$ rsilt_list_item\&_coverDa te $=05 \% 2 \mathrm{~F} 31 \% 2 \mathrm{~F} 2005 \&$ sk $=999799996 \& w \mathrm{chp}=\mathrm{dGLbVIW}-\mathrm{zSkzV} \& \mathrm{md} 5=3 \mathrm{e} 8 \mathrm{e} 86 \mathrm{a} 9853 \mathrm{ed} 5 \mathrm{f} 5 \mathrm{c} 34295 \mathrm{f} 089$ fbcbeb\&ie=/adarticle.pdf [accessed 2010-05-28].

BEAVER, G. \& JENNINGS, P. 2005. Competitive advantage and entrepreneurial power - The dark side of entrepreneurship. Journal of Small Business and Enterprise Development, 12(1):9-23. Available at: Emerald: http://0-www.emeraldinsight.com.innopac.up.ac.za/Insight/viewPDF.jsp?contentType=Article\& Filename $=$ html/Output/Published/EmeraldFullTextArticle/Pdf/2710120101.pdf [accessed 2006-05-11]. BOWER, J. \& GILSON, S. 2003. The social cost of fraud and bankruptcy. Harvard Business Review, 81(12):20-23. Available at: EBSCOHost: Business Source Premier: http://0-web.ebscohost. com.innopac.up.ac.za/ehost/pdfviewer/pdfviewer?vid=3\&hid=15\&sid=dac797fe-9c4e-4432-8174544407463d93\%40sessionmgr13 [accessed 2005-05-218].

CAMERON, K.S., WHETTEN, D.A. \& KIM, M.U. 1987. Organizational dysfunctions of decline. Academy of Management Journal, 30(1):126-138. Available at: EBSCOHost: Business Source Premier: http://0web.ebscohost.com.innopac.up.ac.za/ehost/pdfviewer/pdfviewer?vid=3\&hid=15\&sid=14c34078-a1c5- 455f8334-74b4fb873c7a\%40sessionmgr14 [accessed 2008-10-25].

CANNON, M.D. \& EDMONDSON, A.C. 2005. Failing to learn and learning to fail (intelligently): how great organizations put failure to work to innovate and improve. Long Range Planning, 38:299-319. Available at: ScienceDirect: http://0-www.sciencedirect.com.innopac.up.ac.za/science?_ob=MImg\&_imagekey=B6V6K4G9R2JS-4-1\&_cdi=5817\&_user=59388\&_pii=S0024630105000580\&_orig=browse\&_coverDate= 06\%2F30\%2F2005\& sk=999619996\&view $=\mathrm{c} \& w \mathrm{chp}=\mathrm{dGLbVlz}-\mathrm{SkWA} \& \mathrm{md} 5=\mathrm{a} 1266813686 \mathrm{a} 7 \mathrm{~b}$ 681092215d4d6db948\&ie=/sdarticle.pdf [accessed 2005-09-12].

CARMICHAEL, T. \& STACEY, A. 2006. Perceptions of SAQAs critical cross-field outcomes as key management meta- competencies. South African Journal of Business Management, 37(2):1-15

COLLARD, J.M. 2002. Steering clear of the brink: early warning signs pinpoint business troubles - changing leadership style to accomplish turnaround. The Journal of Private Equity, July:25-31. Available at: EBSCOHost: Business Source Premier: http://0-web.ebscohost.com.innopac.up.ac.za/ehost/ pdfviewer/pdfviewer?vid=1\&hid=105\&sid=a19615dd-855e-4af0-a9ef-ff78f206277f\%40sessionmgr104 [accessed 2004-0-22]. 
CRESSY, R. 2006. Why do most business die young? Small Business Economics, 26(2):103-116. Available at: ProQuest: ABI/INFORM Global: http://0-proquestumi.com.Innopac.up.ac.za/pqdlink?index=6\&did= 973216191\&SrchMode $=3 \&$ sid $=8 \&$ Fmt $=6 \&$ VInst $=$ PROD $\&$ VType $=$ PQD\&RQT $=309 \&$ VName $=$ PQD $\& T S=1$ 274029813\&clientId=15443\&aid=7 [accessed 2006-02-01].

ELENKOV, D. \& FILEVA, T. 2006. Anatomy of a business failure. Accepting the 'bad luck' explanation vs. proactively learning in international business. Cross Cultural Management: An International Journal, 13(2):132-141. Available at: Emerald Insight Management Xtra: http://0-www.emeraldinsight.com. innopac.up.ac.za/Insight/viewPDF.jsp?ContentType=Article\&Filename=html/Output/Published/ EmeraldFullTextArticle/Pdf/1360130203.pdf [accessed 2007-03-21].

FEIXAS, G. \& ALVAREZ, J.M.C. 2006. A manual for the repertory grid. (Version 4,0) Using the GRIDCOR programme. User Manual. Available at: URL: http://www.terapiacognitiva.net/record/ pag/index/htm [accessed 2006-11-06].

FRANKS, J. \& SUSSMAN, O. 2005. Financial innovations and corporate bankruptcy. Journal of Financial Intermediation, 14:283-317. Available at: ScienceDirect: http://0-www.sciencedirect.com.innopac.up. ac.za/science?_ob=MImg\&_imagekey=B6WJD-4F83PGF-1-\&_cdi=6876\&_user=59388\&_pii= S1042957304000622\&_orig $=$ browse\&_coverDate $=07 \% 2 F 31 \% 2 F 2005 \&$ sk $=999859996 \& v i e w=c \& w c h p=d$ GLbVzb-zSkzS\&md5=09531 eb651 f05e-86dedb0afd9502a6b5\&ie=/sdarticle.pdf [accessed 2007-08-28].

FRASER, J.A. 2005. Restructuring Mississippi chemical: a potent solution. Journal of Private Equity, 8(2):45-52. Available at: EBSCOHost: Business Source Premier: http://0-web.ebscohost.com. innopac.up.ac.za/ehost/pdfviewer/pdfviewer?vid=3\&hid=11\&sid=e42a9d81-44d9-4e97-bfc5-f124d33 $3 \mathrm{~d} 37 \mathrm{~d} \% 40$ sessionmgr10 [accessed 2007-08-28].

GILMORE, A., CARSON, D. \& O'DONNELL, A. 2004. Small business owner-managers and their attitude to risk. Marketing Intelligence and Planning, 22(3):349-360. Available at: ProQuest: ABI/INFORM Global: http://0-proquest.umi.com.innopca.up.ac.za/pqdlink?index $=16 \&$ did $=656758981 \&$ SrchMode $=3 \&$ sid $=4 \& \mathrm{Fmt}=6 \& \mathrm{VInst}=\mathrm{PROD} \& \mathrm{VType}=\mathrm{PQD} \& \mathrm{RQT}=309 \& \mathrm{VName}=\mathrm{PQD} \& \mathrm{TS}=1274447409 \&$ clientId $=15443 \& \mathrm{a}$ id $=3$ [accessed 2005-02-17].

GRANT THORTON. 2004a. Steer your business to safety: Heed early financial warning signs. Grant Thornton. Catalyst Management Issues. Available at: URL: http://www.GrantThornton.ca/mgt_papers/ MIP_15.pdf. [accessed 2004-09-22].

HARVEY, N. 2002a. Leveraging value chains. Part 1. Business Education and Management, March:14-15. HOLTZHAUZEN, G.T.D. 2010. Modelling business turnaround strategies using verifier determinants from early warning signs theory. PhD.. Unpublished thesis at University of Pretoria.

IVANOVA, E. \& GIBCUS, P. 2003. The decision-making entrepreneur. Literature Review. EIM Business \& Policy Research, Zoetermeer. Netherlands. Available at: URL: http://www.ondernemerschap.nl/pdfez/N200219.pdf [accessed 2010-01-13].

LOHRKE, F.T., BEDEIAN, A.G. \& PALMER, T.B. 2004. The role of top management teams in formulating and implementing turnaround strategies: a review and research agenda. International Journal of Management Review, 5/6(2):63-90. Available at: EBSCOHost: Business Source Premier: http://0-web.ebscohost.com. innopac.up.ac.za/ehost/pdfviewer/pdfviewer?vid=1\&hid=7\&sid=809053e3-d673-4ba2-bb3ffd95c573cb43\%40sessionmgr12 [accessed 2006-01-11].

LUSSIER, R.N. 1995a. A nonfinancial business success versus failure prediction model for young businesses. Journal of Business Management, 33(1):8-20. Available at: EBSCOHost: Business Source Premier: http://0-web.ebscohost.com.innopac.up.ac.za/ehost/pdfviewer/pdfviewer?vid=2\&hid=119\&sid= 7c212166-f727-4a5f-afe1-fa06f5cbb5b\%40sessionmgr104 [accessed 2009-12-21].

MCGURR, P.T. \& DEVANEY, S.A. 1998. Predicting business failure of retail business: An analysis using mixed industry models. Journal of Business Research, 43(3):169-176. Available at: ScienceDirect: http://0www.sciencedirect.com.innopca.up.ac.za/science?_ob=MImg\&_imagekey=B6V7S-3V546B8-7-

$3 \&$ cdi $=5850 \&$ user $=59388 \&$ pii $=\mathrm{S} 0148296397002221 \&$ orig $=$ browse\& coverDate $=11 \% 2 \mathrm{~F} 30 \% 2 \mathrm{~F} 1998 \&$ _sk=999569996\&view=c\&wchp=dGlbVzWzSkzS\&md5=f40a500a38aff837660dae6447ccb813\&ie=/sdarticl e.pdf [accessed 2005-05-05].

MONCRAZ, E.S. \& KRON, R.N. 1993. Operational analysis: a case study of hotels in financial distress. International Journal of Hospitality Management, 12(2):175-196. Available from: ScienceDirect: http://0www.sciencedirect.com.innopac.up.ac.za/science?_ob=Mlmg\&_imagekey= B6VBH-45K09RY-9$1 \&$ \&cdi $=5927 \&$ user $=59388 \&$ \& pii $=027843199390009$ X\&_orig $=$ browse\&_coverDate $=50 \% 2 \mathrm{~F} 31 \% 2 \mathrm{~F} 1993$ 
\&_sk=999879997\&view $=$ c\&wchp=dGLbVIz-zSkzS\&md5=069de7141ced2c2560f61 cb0a1454110\&ie $=/$ sdarticle.pdf [accessed 2005-05-11].

MOY, J.W. \& LUK, V.W.M. 2003. The life cycle model as a framework for understanding barriers to SME growth in Hong Kong Asia. Asia Pacific Business Review, 10(2):199-220. Available at: EBSCOHost: Business Source Premier: http://0-web.ebscohost.com.innopac.up.ac.za/ehost/pdfviewer/pdfviewer? vid=1\&hid=110\&sid=69dbfaee-4543-416c-b27e-76e31194ce4a\%40sessionmgr111 [accessed 2005-12-14]. MUELLER, G.C., McKINLEY, W., MONE, M.A. \& BARKER III, V.L. 2001. Organizational decline - a stimulus for innovation? Journal of Management Studies, 38(2):235-269. Available at: EBSCOHost: Business Source Premier: http://0-web.ebscohost.com.innopac.up.ac.za/ehost/pdfviewer/pdfviewer? vid=1\&hid=15\&sid=e96647f7-1a31-4a46-846b-9183ac3f3b8d\%40sessionmgr13 [accessed 2009-11-05]. NUTT, P.C. 2004. Expanding the search for alternatives during strategic decision-making. Academy of Management Executive, 18(4):13-28. Available at: EBSCOHost: Business Source Premier: http://0web.ebscohost.com.innopac.up.ac.za/ehost/pdfviewer/pdfviewer?vid=1\&hid=106\&sid=f7763555-26b54019- 9680-ff273a68ec1d\%40Sessionmgr113 [accessed 2005-03-04].

PRETORIUS, M. 2008. When Porter's generic strategies are not enough: Complementary strategies for turnaround situations. Journal of Business Strategy, 29(6):19-28. doi:10.1108/02756660810917200.

PRETORIUS, M. 2009. Defining business decline, failure and turnaround: A content analysis. South African Journal of Entrepreneurship and Small Business Management, 2(10): 1-16.

PRETORIUS, M. 2013. Second generation business rescue scenarios. Available at: http://www.brportal. co.za/_literature_154313/Second_Generation_business_rescue_scenarios_October_2012 [accessed 201305.05].

PRETORIUS, M. \& HOLTZHAUZEN, G.T.D. 2008. Critical variables of venture turnarounds: A liabilities approach. Southern African Business Review, 12(2):87-107.

RICHADRSON, B., NWANKWO, S. \& RICHARDSON, S. 1994. Understanding the causes of business failure crisis: Generic failure types: boiled frogs, drowned frogs, bullfrogs \& tadpoles. Management Decision, 32(4):9-22. Available at: ProQuest: ABI/INFORM Global: http://0-proquest.umi.com. innopac.up.ac.za/pqdink index $=13 \&$ did $=603264 \&$ SrchMode $=3 \&$ sid $=3 \&$ Fmt $=6 \&$ VInst $=$ PROD\&VType $=$ $\mathrm{PQD} \& \mathrm{RQT}=309 \&$ VName=PQD\&TS=1274178489\&clientId=15443\&aid=3 [accessed 2005-02-17].

SERFONTEIN, S., BASSON, J.S. \& BURDEN, J. 2009. Mapping the transformation from a traditional to an entrepreneurial organisation: A South African case. SA Journal of Human Resource Management/SA Tydskrif vir Menslikehulpbronbestuur, 7(1):49-62.

SHARMA, D.S. 2001. The role of cash flow information in predicting corporate failure: the state of the literature. Managerial Finance, 27(4):3-28. Available at: ProQuest: BI/INFORM Global: http://0-proquest. umi.com.innopac.up. ac.za/pqdweb? index $=0 \& d i d=283030011 \&$ SrchMode $=1 \&$ sid $=1 \& F m t=6 \&$ VInst $=$ PROD\&VType=PQD\&RQT=309\&VName $=$ PQD\&TS=1274445802\&clientId=15443 [accessed 200502-17].

SHARMA, S. \& MAHAJAN, V. 1980. Early warning indicators of business failure. Journal of Marketing, 44(4):80-89. Available at: jstor: stable url: http://0-www.jstor.org.innopac.up.ac.za/stable/pdfplus/ 1251234.pdf [accessed 2005-02-17].

SINGER, B. 1995. Contours of Development. Journal of Business Venturing, 10(1):303-329.

STEAD, E. \& SMALLMAN, C. 1999. Understanding business failure: Learning and un-learning lessons from: industrial crises. Journal of Contingencies and Crisis Management, 7(1):1-18. Available at: EBSCOHost: Business Source Premier: http://0-web.ebscohost.com.innopac.up.ac.za/ehost/pdfviewer/ pdfviewer?vid=1\&hid=13\&sid=ea9b4e18-b1c6-418c-8545-6b3db9537c87\%40sessionmgr13 [accessed 200211-29].

STUBBART, C. 1982. Are environmental scanning units effective? Long Range Planning, 15(3):139-145. Available at: ScienceDirect: http://0-www.sciencedirect.com.Innopac.up.ac.za/science?_ob=MImg\&_ imagekey=B6V6K-460P3YH-1B1\&_cdi $=5817 \& \_u s e r=59388 \&$ pii $=0024630182900358 \&$ orig $=$ search \& 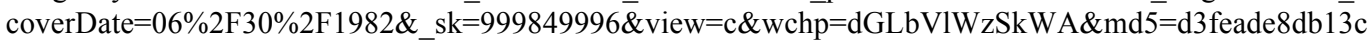 380dd25ec16ef95056f\&ie=/sdarticle.pdf [accessed 2010-04-22].

TANG, T. \& CHI, L. 2005. Neutral networks analysis in business failure prediction of Chinese importers: A between-countries approach. Expert Systems with Applications, 29(2):244-255. Available at: Science Direct: http://0-www.sciencedirect.com.innopac.up.ac.za/science?_ob=MImg\&_imagekey=B6V03-4FYYYWM-15\&_cdi $=5635 \&$ _user $=59388 \&$ pii $=$ S0957417405000412\&_orig $=$ browse\&_coverDate $=08 \% 2 F 31 \% 2 F 2005 \&$ 


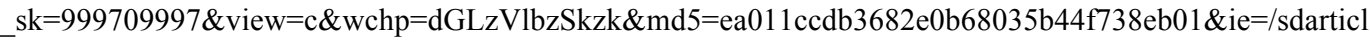
e.pdf [accessed 2006-06-06].

UEDA, M. 2004. Banks versus venture capital: project evaluation, screening and expropriation. The Journal of Finance, 59(2):606-621. Available at: EBSCOHost: Business source Premier: http://0-web.ebscohost. com.innopac.up.ac.za/ehost/pdfviewer/pdfviewer?hid=8\&sid=09baca2b-99ae-477c-b360-8424285bfbb3\% 40sessionmgr14\&vid=3 [accessed 2008-06-25].

YIN, R.K. 2003. Case study research. Designs and methods: Applied social research methods. ( ${ }^{\text {rd }}$ ed.) Series Volume 5. London: Sage. 